\title{
Friendship and Romantic Relationship Qualities in Emerging Adulthood: Differential Associations with Identity Development and Achieved Adulthood Criteria
}

\author{
Carolyn McNamara Barry \\ Loyola College in Maryland \\ Stephanie D. Madsen \\ McDaniel College \\ Larry J. Nelson \\ Brigham Young University - Provo \\ Jason S. Carroll \\ Brigham Young University - Provo, jcarroll@byu.edu \\ Follow this and additional works at: https://scholarsarchive.byu.edu/facpub \\ Ecrah Badger

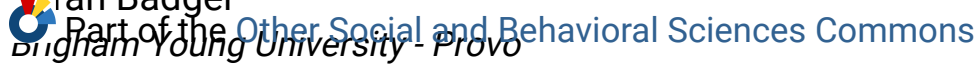

\section{Original Publication Citation}

Barry, C.M., Madsen, S. D., Nelson, L. J., Carroll, J. S.,\& Badger, S.* (2009). Friendship and Romantic Relationship Qualities in Emerging Adulthood: Differential Associations with Identity Development and Achieved Adulthood Criteria. Journal of Adult Development, 16, 209-222.

\section{BYU ScholarsArchive Citation}

Barry, Carolyn McNamara; Madsen, Stephanie D.; Nelson, Larry J.; Carroll, Jason S.; and Badger, Sarah, "Friendship and Romantic Relationship Qualities in Emerging Adulthood: Differential Associations with Identity Development and Achieved Adulthood Criteria" (2009). Faculty Publications. 4344.

https://scholarsarchive.byu.edu/facpub/4344

This Peer-Reviewed Article is brought to you for free and open access by BYU ScholarsArchive. It has been accepted for inclusion in Faculty Publications by an authorized administrator of BYU ScholarsArchive. For more information, please contact ellen_amatangelo@byu.edu. 


\title{
Friendship and Romantic Relationship Qualities in Emerging Adulthood: Differential Associations with Identity Development and Achieved Adulthood Criteria
}

\author{
Carolyn McNamara Barry $\cdot$ Stephanie D. Madsen · \\ Larry J. Nelson · Jason S. Carroll · \\ Sarah Badger
}

Published online: 17 April 2009

(C) Springer Science+Business Media, LLC 2009

\begin{abstract}
This study examined how emerging adults' identity development and achievement of adulthood criteria were related to qualities of their friendships and romantic relationships. Participants included 710 emerging adults (ages 18-26). Results indicated that identity achievement was related positively to four romantic relationship qualities, but not to any friendship qualities. Several achieved adulthood criteria were related positively to romantic relationship qualities; however, achieved adulthood criteria were related negatively to friendship qualities. It appears that progress on salient developmental tasks of adulthood carries important implications for emerging adults' social relationships, but in ways that are more differentiated than commonly assumed.
\end{abstract}

Keywords Relationship quality - Romantic relationship · Friendship $\cdot$ Identity $\cdot$ Adulthood criteria

Portions of this study were presented at the 2nd Conference on Emerging Adulthood in Miami, FL, February 2005.

C. M. Barry $(\bowtie)$

Department of Psychology, Loyola College in Maryland, Beatty 212, 4501 N. Charles St., Baltimore, MD 21210, USA

e-mail: cbarry@loyola.edu

\section{S. D. Madsen}

Department of Psychology, McDaniel College, Westminster, MD, USA

L. J. Nelson · J. S. Carroll · S. Badger

School of Family Life, Brigham Young University, Provo, UT, USA

\section{Introduction}

In recent years, scholars have recognized that individuals from 18 years of age through the middle 20s experience particular challenges and opportunities (Cohen et al. 2003; Roisman et al. 2004). In fact, Arnett (2000) contends that as a result of demographic shifts in industrialized nations, many of these individuals are experiencing a new stage in the lifespan known as "emerging adulthood." Erikson's (1968) psychosocial theory specifies that these emerging adults are facing the intimacy against isolation crisis; however, in reality the task of forming intimate partnerships is complicated by competing developmental demands. Most emerging adults not only are engaged in forming intimate relationships, but are also doing so while establishing secure identities (Erikson 1968), managing other close relationships such as friendships (Hartup and Stevens 1997), and gradually assuming adult roles in society (Havighurst 1948). In an effort to examine emerging adults in a more holistic fashion and to capture the multidimensional nature of their close relationships, the current study examined the interrelations of identity development and the achievement of adulthood criteria (e.g., becoming self-reliant and complying with societal norms) with qualities of emerging adults' romantic relationships and friendships.

\section{Interpersonal Relationships in Emerging Adulthood}

Most emerging adults have both close friendships and romantic relationships (Collins and Madsen 2006), and some similarities between these two forms of relationships have been reported. Emerging adults consider their friends and their romantic partners to be important persons within their social networks (Fraley and Davis 1997). They spend 
considerable amounts of time with them (particularly their romantic partners; Collins and Laursen 2004), and qualities of both relationships have been associated with happiness (Demir 2008; Demir and Weitekamp 2006). Both relationships are voluntary and can be transient given that participants freely begin and end these associations (Laursen and Bukowski 1997).

Despite these similarities, relationships with friends and romantic partners serve distinct functions (Furman and Buhrmester 1992). Friendships tend to satisfy social integration needs (i.e., companionship), feelings of worth, and to a lesser degree, intimacy. Romantic relationships primarily satisfy intimacy needs and provide emotional support (Weiss 1974). These functions may change over time and in response to individual developmental needs (Monck 1991).

Despite differing functions, friendships and romantic relationships do not exist independently, but rather are embedded within an ongoing social experience (Connolly and Johnson 1996; Lefkowitz et al. 2004). The overlapping, yet unique features of friendships and romantic relationships in emerging adulthood suggest a need for multidimensional context-specific models of development (Berndt 2004; Collins and Madsen 2006). Given the unique developmental demands of emerging adulthood and the unique functions of friendships and romantic relationships, we might expect the qualities of these relationships to be differentially linked to individuals' achievement of adult qualities (i.e., a developed identity and the adoption of adult roles). That is, emerging adults' efforts to forge meaningful identities and take on new adult roles and responsibilities should foster close relationships in some respects, but pose barriers to maintaining close relationships in other respects. Theoretical and empirical work on dyadic withdrawal and identity development suggests differential predictions regarding specific relationship qualities of friendships and romantic partnerships.

\section{Dyadic Withdrawal Hypothesis and Relationship Qualities}

Classic research by Sullivan (1953) and Dunphy (1963) suggests that peer relationships support the development of romantic relationships in adolescence, but are less prominent once romantic relationships are established. Johnson and Leslie (1982) formalized this idea with the Dyadic Withdrawal Hypothesis, predicting that romantically involved couples would withdraw from their friendship networks. Although peers remain frequent companions throughout adolescence (Richards et al. 1998), the presence of a romantic relationship has been associated with spending less time with friends (Zimmer-Gembeck 1999). Similarly, ample research supports variations of the Dyadic
Withdrawal Hypothesis in early adulthood (see Johnson and Leslie 1982; Milardo et al. 1983; Surra 1985).

Dyadic withdrawal from social networks primarily has been explained by newly formed couples' need to establish intimacy, presumably at the expense of time spent in other close relationships such as friendships. However, it is also possible that dyadic withdrawal is associated with individual developmental needs. Just as people select patterns of leisure behavior based on salient needs (Iso-Ahola 1980), people "tend to construct relationships consistent with their psychological goals, cognitive abilities, and social demands" (Laursen and Bukowski 1997, p. 748; see Sanderson and Cantor 1997). Extensive time spent with friends may fill needs of identity development (i.e., supporting periods of exploration in a familiar context), but may be at cross purposes with intimacy needs that require intensive attention to establishing a close romantic partnership (Feldman et al. 2000). Similarly, individuals who perceive themselves to be adults are less self-focused, more family focused, and more certain of the characteristics they desire in a romantic partner compared to those who do not perceive themselves to be adults (Nelson and Barry 2005). The adoption of adult roles may free up time that previously was focused on oneself to now be invested in romantic relationships. Indeed research suggests that young people may see a developmental process in which they focus first on becoming self-reliant adults and then turn toward more serious relationships (Carroll et al. 2007), which would result in less time divested in friendships. Moreover, as adolescents' transition to romantic partnership in young adulthood (ages 21-23) and intimacy becomes more salient, these young adults experience greater emotional adjustment and stability in these romantic relationships (Meeus et al. 2007). Thus, individuals who are more certain of their identities and who have achieved more criteria for adulthood are expected to have more positive qualities in romantic relationships and fewer positive qualities in friendships, across a variety of relationship dimensions. Those friendship qualities most dependent on the devotion of time and attention (i.e., companionship and nurturance) are expected to be compromised in the friendships of these individuals.

Although sheer time spent with a friend may be a marker of feelings about that friendship before a romantic relationship enters the social network, it may not be the most important aspect afterwards (Zimmer-Gembeck 1999). Many of the characteristics and qualities that define close friendships may change across the transition to adulthood or based on the presence or absence of a romantic relationship in the social network. Further, while qualities of romantic relationships are being newly established in emerging adulthood, some friendship qualities may have been established earlier in adolescence (Hartup 
and Stevens 1997). Thus, the friendship qualities of satisfaction (i.e., feelings of how good a relationship is) and alliance (i.e., whether the relationship is expected to continue) would not be expected to relate to emerging adults' progress on identity development or achieved adulthood criteria. That is, while alliance to the friendship and feelings of satisfaction may be entrenched from years of a shared history, more immediate friendship qualities such as companionship and nurturance likely suffer with the concordant changes of adopting adult roles. Further, expectations regarding one's time investment in the friendship may be adjusted once a romantic partner enters the social network, protecting feelings of satisfaction and alliance in the friendship.

\section{Erikson's Psychosocial Theory of Development} and Intimacy

Alternative theoretical and empirical work suggests that progress on identity development and the achievement of criteria for adulthood might be associated with some positive relationships qualities for both friendships and romantic relationships. Erikson's $(1968,1982)$ psychosocial theory contends that progress on identity development (beginning in adolescence and continuing into early adulthood) should allow for greater intimacy in all close relationships, not just romantic ones. Contemporary researchers also have argued that progress toward a mature identity and the experience of mature intimacy take place concurrently (Paul and White 1990; Seginer and Noyman 2005), and are developmental tasks of emerging adulthood. Erikson (1963) and others (Dyk and Adams 1990; Markstrom and Kalmanir 2001; Matula et al. 1992; Montgomery 2005) have documented the link between identity and intimacy in romantic relationships. Thus, greater intimacy in close relationships also was expected to be associated with progress in adopting adult roles, as emerging adults skilled at intimacy should be more secure at interacting with others while remaining true to their own beliefs (Paul and White 1990), a hallmark of adulthood (Arnett 2003, 2004).

\section{Gender Differences}

Emerging adults tend to perceive and experience close relationships differently based, in part, upon gender. For example, college women indicate that they provide more benefits (e.g., types of support) to their friends than do college men, and college men indicate that there are more costs (e.g., wasted time, boredom) to their friendships than do college women (Hays 1989). In addition, shared activities are an important component of men's friendships (Sherman et al. 2000), whereas emotional support and intimacy are particularly important to women's relationships (Carbery and Buhrmester 1998; Ginsberg and Gottman 1986). Nonetheless, intimacy in both types of relationships increases for both genders across young adulthood (ages 26-31 years; Reis et al. 1993).

Behaviors within romantic relationships also have been shown to vary as a function of gender, such that men report greater agreeable behavior with their romantic partners than do women, but women report more quarrelsome behavior with their romantic partners than do men (Suh et al. 2004). According to Collins et al. (2002), women who had an avoidant attachment to their male romantic partners were less satisfied and more troubled about their relationship than men who had an avoidant attachment to their female romantic partners. Taken together, recent research has started to shed light on how the form and function of relationships vary based on gender, but much less is known about how these differences are associated with other important aspects of emerging adulthood.

\section{Overview of the Study}

In the current study, data were collected from emerging adults to examine the intersection of identity development and achievement of adulthood criteria with qualities of close relationships with romantic partners and friends. We posited the differential prediction, based on the developmental tasks of emerging adulthood (Havighurst 1948) and the Dyadic Withdrawal Hypothesis (Johnson and Leslie 1982), that emerging adults who have engaged in more identity exploration and achieved more adulthood criteria would have romantic relationships that are more positive across a variety of relationship qualities, but friendships that are less positive in these qualities, particularly timeintensive qualities such as companionship and nurturance. More enduring relationship qualities such as relationship satisfaction and alliance were expected to defy this pattern, as was the quality of intimacy. Instead, we expected that friendship satisfaction and alliance would not be related to identity and adulthood criteria, whereas intimacy would be related positively to identity and adulthood criteria for both friendships and romantic relationships. Given the noted gender differences in emerging adults' close relationships, relationship qualities were explored by gender as well.

\section{Method}

Participants

Participants for this study were drawn from an ongoing study of emerging adults and their parents that was entitled 
"Project READY" (Researching Emerging Adults' Developmental Years). This project is an ongoing, collaborative, multi-site study that is being conducted by a consortium of developmental and family scholars.

The sample used in the current study consisted of 710 undergraduate and graduate students $(61.4 \%$ women, $38.6 \%$ men) recruited from six college sites. The sample ranged from 18 to 26 years with the mean age of 19.93 years $(S D=1.77)$ for women and 19.98 years $(S D=1.83)$ for men. Eighty-one percent of the participants were European American, 3.4\% were African American, $7.8 \%$ were Asian American, 3.4\% were Latino American, and $4.6 \%$ indicated that they were "mixed/ biracial," Native American/American Indian, or of an "other" ethnicity. All of the participants were unmarried (6.6\% cohabiting with a partner in an intimate relationship) and $90 \%$ reported living outside their parents' home in an apartment, house, or dormitory. Of 710 students, 79.3\% $(n=563)$ had a current romantic partner and $98.7 \%$ had a best friend $(n=701)$. Regarding self-reported dating status, $20.7 \%$ of the sample were not currently dating, $27.2 \%$ were dating casually, $45.8 \%$ had an exclusive relationship (i.e., boy/girlfriend), and $6.3 \%$ were engaged. Also, most emerging adults reported that their best friendships were longer in duration ( $92.7 \%$ lasting more than a year) than their romantic relationships $(34.2 \%$ lasting more than a year).

\section{Procedure}

Participants completed the Project READY questionnaire through the Internet (see http://www.projectready.net). The use of an online data collection protocol facilitated unified data collection across multiple university sites. Participants were recruited through faculty's announcement of the study in undergraduate and graduate courses. Professors at the various universities were provided with a student handout that had a brief explanation of the study and directions for accessing the online survey. Interested students then accessed the study website with a location-specific recruitment code. Informed consent was obtained online, and only thereafter could the participants begin the questionnaires. Each participant was asked to complete a survey battery of 448 items within a single setting, which took typically 1 hour to complete. Sections of the survey addressed topic areas such as background information, family-of-origin experiences, self-perceptions, risk behaviors, and prosocial behaviors. Most participants were offered course credit or extra credit for their participation. In a small number of cases ( $\approx 5 \%$ ), participants were offered small monetary compensation (i.e., $\$ 10$ gift certificates) for their participation.
Measures

All measures were assessed through self-report instruments administered via the Internet.

\section{Relationship Qualities}

The short-version of the Social Provisions Questionnaire (Carbery and Buhrmester 1998) was used to assess qualities of friendships and romantic relationships. Participants rated three items for each of the nine subscales regarding both their best friend and their romantic partner. Ratings were made on a Likert-type scale that ranged from Little or None (1) to The Most (5). Sample items for each subscale include "How much free time do you spend together?" for companionship; "How much does this person make you feel admired and respected?" for worth; "How sure are you that your relationship will continue in the years to come?" for alliance; "How much do you take care of this person?" for nurturance; "How much does this person really care about you?" for affection; "How much do you tell this person everything?" for intimacy; "How good is your relationship with this person?" for relationship satisfaction; "How much does this person help you figure out or fix things?" for aid; and "How often do you turn to this person for support with personal problems?" for emotional support. Cronbach's alpha for friendship qualities subscales ranged from .76 to .92 (mean $\alpha=.82$ ), whereas Cronbach's $\alpha$ for romantic relationship qualities ranged from .72 to .98 (mean $\alpha=.94$ ).

\section{Identity Statuses}

Participants completed a shortened version of the Ego Identity Process Questionnaire (Balistreri et al. 1995), which consisted of 12 positively worded and 8 negatively worded items tapping various domains of identity development including occupation, religion, politics, and values. Participants rated each statement on a 6-point Likert-type scale from Strongly Disagree to Strongly Agree, e.g., "I have considered adopting different kinds of religious beliefs." for exploration $(\alpha=.69)$; and "I have definitely decided on the occupation I want to pursue." for commitment $(\alpha=.60)$. Items for each subscale were totaled, and median splits were computed; the reliabilities are consistent with Balistreri et al. for their short-form measure. As articulated in the study of Balistreri et al. (1995), inspection of subscales scores resulted in a variable of identity status, wherein each individual was labeled as one of four possible identity status codes. Specifically, identity achievement signified participants with both identity exploration and commitment scores above the median (exploration median $=39 ;$ commitment median $=42$; 
$29.3 \%$ of sample); identity foreclosure signified participants with identity exploration scores below the median, but identity commitment scores above the median $(24.7 \%$ of the sample); identity moratorium signified participants with identity exploration scores above the median, but identity commitment scores below the median $(24.8 \%$ of the sample); and identity diffusion signified participants with both identity exploration and commitment scores below the median (21.2\% of the sample).

\section{Achievement of Adulthood Criteria}

Participants were asked to indicate the extent to which they felt that they had achieved 33 criteria for adulthood. For 22 items (e.g., financially independent from parents), they could respond on a scale of Not True (1) to Very True (3). For 11 items (e.g., have purchased a house), they could respond with either 1 (No, Does Not Apply to Me) or 2 (Yes, Applies to Me). Drawing upon prior research (Arnett 1997), the achieved criteria of adulthood were formed into six categories: independence, interdependence, role transitions, norm compliance, chronological transitions, and family capacities (see Table 1).

\section{Results}

\section{Preliminary Analyses}

In order to examine the relation between adulthood indicators and qualities of friendships and romantic relationships, respectively, identity status and achieved criteria for adulthood were correlated with the relationship qualities (companionship, worth, alliance, nurturance, affection, intimacy, relationship satisfaction, aid, and emotional support); listwise deletion was used. Since identity status was a categorical variable representing four statuses, three dummy variables were created, and labeled according to what category was designated as "1" (e.g., identity achievement) rather than " 0 " (e.g., identity foreclosure, moratorium, and diffusion). These dummy-coded variables were used for all analyses. The results for friendships are presented in Table 2; findings for romantic relationships are presented in Table 3. Women were more likely to report achievement of their identity as well as the adulthood criteria of interdependence and norm compliance, and less likely to report achievement of the adulthood criterion category of role transitions. Gender also was correlated with relationship qualities, such that women reported five friendship qualities and four romantic relationship qualities to be higher than did men. Regarding identity statuses, identity achievement was correlated positively with the friendship quality of affection and all nine romantic
Table 1 Achieved criteria for adulthood categories

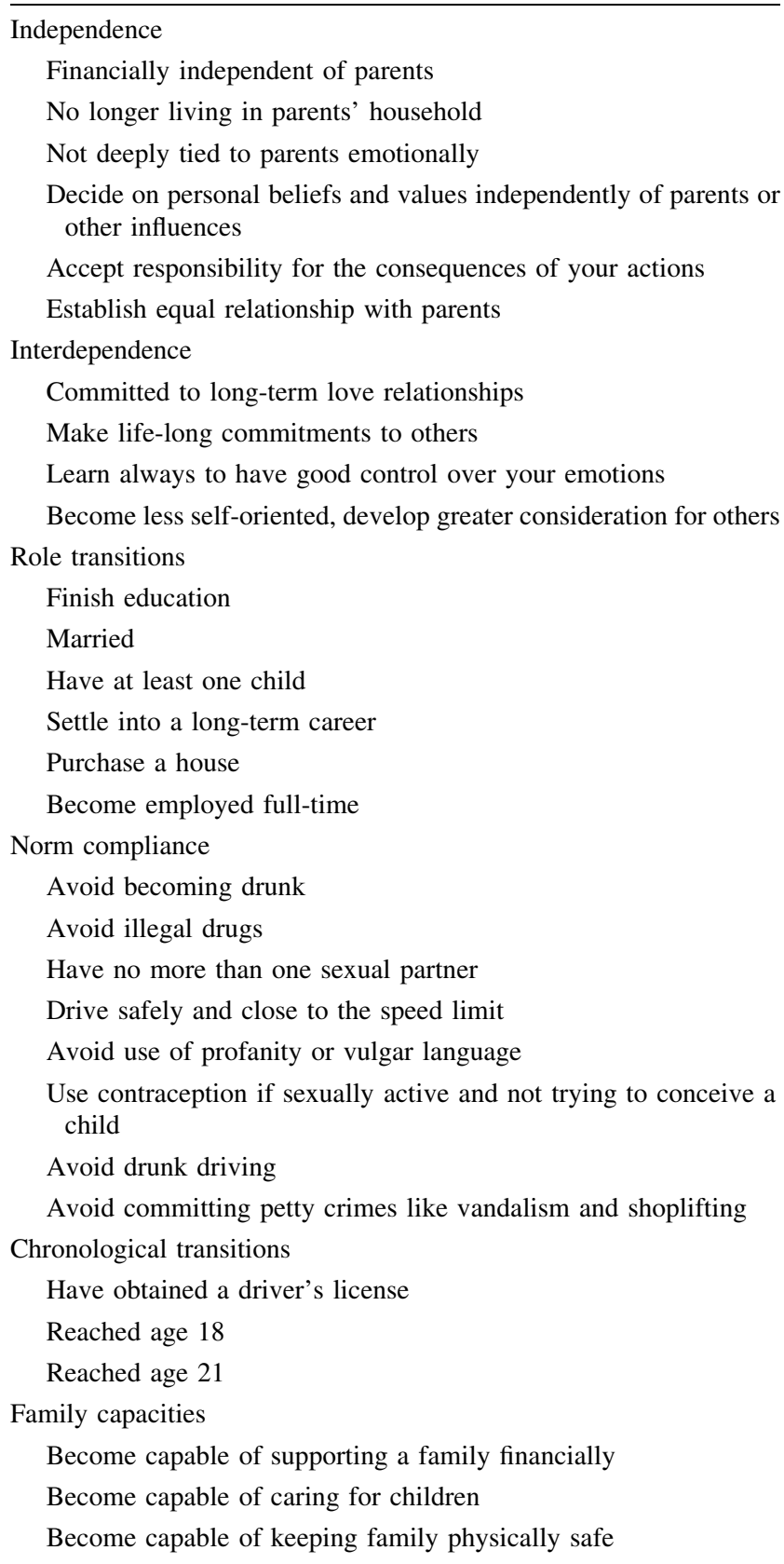

relationship qualities. Generally, achieved adulthood criteria were correlated negatively with friendship qualities, and correlated positively with romantic relationship qualities.

\section{Associations with Friendship Qualities}

A multiple regression analysis was computed on each of the nine friendship qualities. For each analysis, gender, identity status (with three dummy-coded variables), and the seven categories for the achievement of adulthood criteria 


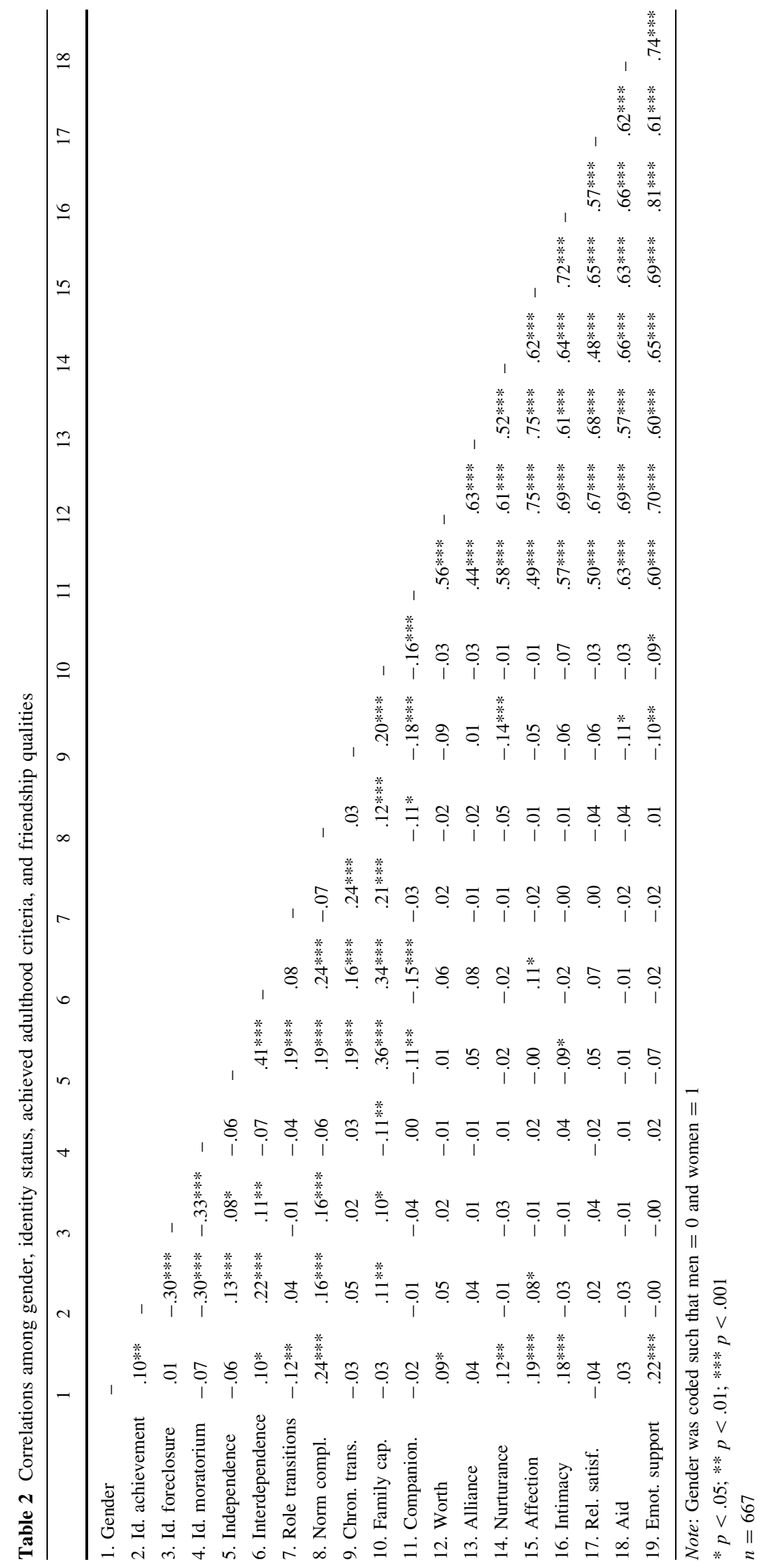




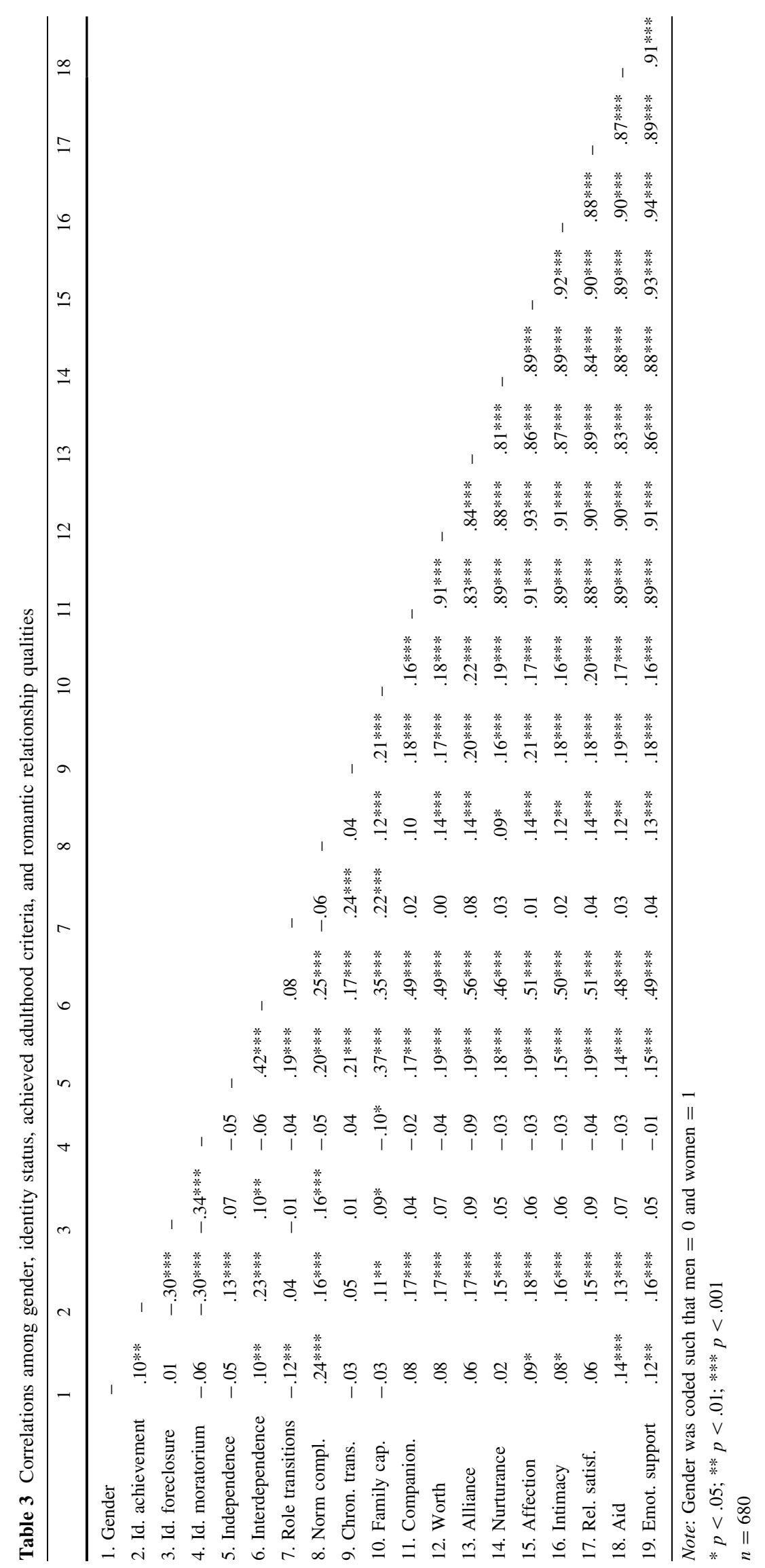


Table 4 Results of multiple regression analyses on friendship qualities

\begin{tabular}{|c|c|c|c|c|c|c|c|c|c|}
\hline Variables & Companionship & Worth & Alliance & Nurturance & Affection & Intimacy & $\begin{array}{l}\text { Relationship } \\
\text { satisfaction }\end{array}$ & Aid & $\begin{array}{l}\text { Emot. } \\
\text { support }\end{array}$ \\
\hline Gender & .00 & .10 & .05 & $.15^{* * *}$ & $.19 * * *$ & $.19 *$ & -.03 & .05 & $.23 * * *$ \\
\hline \multicolumn{10}{|l|}{ Identity status } \\
\hline Achievement & .03 & .07 & .04 & -.01 & $.09 \dagger$ & -.03 & .04 & -.03 & .01 \\
\hline Foreclosure & .00 & .07 & .04 & -.02 & .04 & .00 & .06 & -.02 & .02 \\
\hline Moratorium & .00 & .04 & .02 & .03 & .07 & .04 & .02 & .00 & .04 \\
\hline \multicolumn{10}{|c|}{ Achieved adulthood criteria } \\
\hline Independence & .01 & .03 & .07 & .04 & -.01 & -.06 & .07 & .04 & .05 \\
\hline Interdependence & $-.08 \dagger$ & .08 & $.08 \dagger$ & -.01 & $.12 * *$ & .02 & $.09 *$ & .02 & -.01 \\
\hline Role transitions & .03 & .05 & -.01 & .03 & .02 & .05 & .01 & .01 & .00 \\
\hline Norm compliance & -.05 & -.05 & -.05 & -.06 & $-.10^{*}$ & -.01 & -.05 & -.03 & -.06 \\
\hline $\begin{array}{c}\text { Chronological } \\
\text { transitions }\end{array}$ & $-.14 * * *$ & $-.11 * *$ & .01 & $-.14 * *$ & -.06 & -.03 & -.07 & $-.09 *$ & -.01 \\
\hline Family capacities & $-.10 *$ & -.05 & -.07 & .04 & -.03 & -.04 & -.07 & -.02 & $-.07 \dagger$ \\
\hline Total $R^{2}$ & .05 & .03 & .02 & .04 & .06 & .05 & .02 & .02 & .06 \\
\hline $\begin{array}{l}F \\
(\mathrm{df})\end{array}$ & $\begin{array}{c}3.80 * * * \\
(10,666)\end{array}$ & $\begin{array}{c}2.12 * \\
(10,665)\end{array}$ & $\begin{array}{l}1.15 \\
(10,665)\end{array}$ & $\begin{array}{c}2.73 * * * \\
(10,665)\end{array}$ & $\begin{array}{c}4.32 * * * \\
(10,663)\end{array}$ & $\begin{array}{c}3.13 * * * \\
(10,666)\end{array}$ & $\begin{array}{l}1.47 \\
(10,663)\end{array}$ & $\begin{array}{c}.984 \\
(10,667)\end{array}$ & $\begin{array}{r}.38 * * * \\
(10,667)\end{array}$ \\
\hline
\end{tabular}

Note: $n=678$. Standardized beta weight values are shown. The ANOVA for the regression on alliance and relationship satisfaction was not significant, $p>.05$

$\dagger p<.10 ; * p<.05 ; * * p<.01 ; * * * p<.001$

were entered simultaneously. Interactions of achievement of adulthood criteria $\times$ identity status were examined for each friendship quality and found to be nonsignificant; thus, they were not described in these analyses. The ANOVAs for six of the nine regressions were significant. As shown in Table 4, female emerging adults reported greater nurturance, affection, intimacy, and emotional support from their friendships than did male emerging adults. Identity statuses were not significant predictors of friendship qualities. Compared to emerging adults with less achievement in these adulthood criteria, emerging adults with greater achievement of chronological transitions and family capacities reported less companionship from their friendships, and emerging adults with greater achievement of the adulthood criteria categories of chronological transitions reported less worth, nurturance, and aid in their friendships. Finally, emerging adults who reported greater achievement of the adulthood criteria category of interdependence and less achievement in norm compliance reported more affection about their friendships.

\section{Associations with Romantic Relationship Qualities}

A multiple regression analysis was computed on each of the nine romantic relationship qualities. For each analysis, gender, identity status (with three dummy-coded variables), and the seven categories for the achievement of adulthood criteria were entered simultaneously. Interactions of achievement of adulthood criteria $\times$ identity status were examined for each romantic relationship quality and found to be nonsignificant; thus, they are not described here. The ANOVAs for all nine regressions were significant. As shown in Table 5, gender (i.e., being a woman) was associated with the romantic relationship quality of aid only. For the identity dummy-coded variables, only identity achievement positively predicted companionship, worth, affection, and emotional support. Compared to emerging adults with less achievement of particular adulthood criteria categories, emerging adults with greater achievement of the adulthood criteria category of interdependence and chronological transitions reported significantly greater levels on all nine romantic relationship qualities. Emerging adults with less achievement in the adulthood category of independence reported lower levels of alliance, intimacy, aid, and emotional support about their romantic relationships than did those with greater achievement in this category.

\section{Discussion}

The purpose of this study was to examine the degree to which emerging adults' progress on identity development and achieved adulthood criteria were related to the qualities of friendships and romantic relationships. It was hypothesized that emerging adults who had made greater progress on identity development and adulthood criteria generally would report more positive qualities in their romantic 
Table 5 Results of multiple regression analyses on romantic relationship qualities

\begin{tabular}{|c|c|c|c|c|c|c|c|c|c|}
\hline Variables & Companionship & Worth & Alliance & Nurturance & Affection & Intimacy & $\begin{array}{l}\text { Relationship } \\
\text { satisfaction }\end{array}$ & Aid & $\begin{array}{l}\text { Emot. } \\
\text { support }\end{array}$ \\
\hline Gender & .03 & .02 & .00 & -.02 & .03 & .02 & .01 & $.10 * *$ & $.07 \dagger$ \\
\hline \multicolumn{10}{|l|}{ Identity status } \\
\hline Achievement & $.08^{*}$ & $.10^{*}$ & .05 & .06 & $.10^{*}$ & $.08 \dagger$ & $.07 \dagger$ & .04 & $.08 *$ \\
\hline Foreclosure & .03 & .06 & .04 & .03 & .05 & .04 & $.07 \dagger$ & .04 & .04 \\
\hline Moratorium & .03 & .03 & -.03 & .02 & .04 & .02 & .03 & .02 & .05 \\
\hline \multicolumn{10}{|c|}{ Achieved adulthood criteria } \\
\hline Independence & -.05 & -.03 & $-.09 * *$ & -.04 & -.04 & $-.09 *$ & -.06 & $-.09 *$ & $-.08 *$ \\
\hline Interdependence & $.49 * * *$ & $.46 * * *$ & $.55^{* * *}$ & $.45 * * *$ & $.48 * * *$ & $.51 * * *$ & $.49 * * *$ & $.47 * * *$ & $.49 * * *$ \\
\hline Role transitions & -.04 & -.05 & .02 & -.03 & -.05 & -.03 & -.02 & -.01 & -.00 \\
\hline Norm compliance & -.04 & .00 & .00 & -.04 & -.01 & -.02 & .00 & -.02 & -.01 \\
\hline $\begin{array}{l}\text { Chronological } \\
\text { transitions }\end{array}$ & $.12 * * *$ & $.10^{* *}$ & $.11 * * *$ & $.09 *$ & $.14 * * *$ & $.11 * * *$ & $.10 * *$ & $.12 * * *$ & $.11 * * *$ \\
\hline Family capacities & -.02 & .01 & .01 & .03 & -.01 & -.01 & .02 & .01 & -.01 \\
\hline Total $R^{2}$ & .26 & .26 & .33 & .23 & .28 & .27 & 1.28 & .26 & .27 \\
\hline$F$ & $23.69 * * *$ & $22.85 * * *$ & $33.15 * * *$ & $19.83 * * *$ & $26.58 * * *$ & $25.11 * * *$ & $25.82 * * *$ & $23.11 * * *$ & $24.22 * * *$ \\
\hline (df) & $(10,669)$ & $(10,669)$ & $(10,669)$ & $(10,669)$ & $(10,669)$ & $(10,669)$ & $(10,669)$ & $(10,669)$ & $(10,669)$ \\
\hline
\end{tabular}

Note: $n=680$. Standardized beta weight values are shown

$\dagger p<.10$; * $p<.05$; ** $p<.01$; *** $p<.001$

relationships and less positive qualities in their friendships, particularly with respect to relationship qualities that depended upon a substantial time investment in the relationship (i.e., companionship and nurturance). The friendship qualities of alliance and relationship satisfaction were predicted to be exceptions to this pattern. Further, progress on identity development and adulthood criteria was expected to be associated with high levels of intimacy in both friendships and romantic relationships.

The results generally supported these hypotheses; identity achievement was associated positively with four qualities of romantic relationships (i.e., companionship, worth, affection, and emotional support), but was not associated with any friendship qualities. Several achieved adulthood criteria (e.g., interdependence) were associated positively with some, and in some cases, all romantic relationship qualities measured. In contrast, having achieved considerably more adulthood criteria (e.g., family capacities, norm compliance, and chronological transitions) was associated with poorer friendship qualities.

\section{Differential Predictions for Friendship Versus \\ Romantic Relationship Qualities}

In this study, the differential prediction involving high levels of romantic relationship qualities, but low levels of friendship qualities was supported. Additionally, the three sets of specific predictions generally were supported, such that identity development and achieved adulthood criteria were related: (a) positively to the romantic relationship (but not friendship) qualities of companionship and nurturance, (b) nonsignificantly to the relationship satisfaction and alliance within a friendship, and (c) positively to romantic relationship quality of intimacy. Thus, the results are consistent with existing theories (e.g., Erikson 1968; White et al. 1986) and empirical research (e.g., Carbery and Buhrmester 1998) that indicate a greater focus on romantic relationships than friendships during emerging adulthood. Given the cross-sectional design used in this study, longitudinal studies that include qualitative measures are an essential next step to clarify whether and how emerging adults' attention to and their experiences of their friendships and romantic relationships changes during this time period.

This future research should consider three scenarios that might explain the nature of emerging adults' close relationships. First, perhaps one function of friendships during this period is to help emerging adults navigate the transition to adulthood, and, therefore, to assist them in achieving the criteria for adulthood. For instance, peer networks (that include opposite-sex friends) channel heterosexual adolescents to romantic partners (Feiring 1999). However, friendships then are ill-suited for supporting emerging adults once they have achieved certain markers of adulthood. In other words, friendships may become less useful as one approaches adult status (as indicated by having achieved numerous of the markers and identity achievement) and immediately after one has taken on new 
adult responsibilities. As a result, a primary focus on adult matters could result in friendships with fewer positive qualities. Thereafter, romantic partners may be most useful in supporting emerging adults for subsequent developmental tasks of establishing a marriage, family, and a career. A second possibility is that a drop in friendship quality itself might be associated with emerging adults' focus on more satisfying and intimate romantic relationships (e.g., Carroll et al. 2007). The third and most likely option is that these two factors work in tandem to account for the decrease in some aspects of friendship quality and increase in romantic relationship quality. Thus, future scholars need to posit and test complex models involving intrapersonal, individual, and societal factors to explain how emerging adults organize their close relationships.

\section{Unexpected Findings}

In this study, three exceptions were found for the posited relations: (a) identity statuses and the achieved adulthood criteria were not related positively to intimacy in friendships, (b) the adulthood criterion of independence was related negatively to the romantic relationship qualities of alliance, intimacy, aid, and emotional support, and (c) the adulthood criterion of interdependence was related positively to the friendship qualities of affection and relationship satisfaction.

Erikson (1963) theorized that resolution of one's identity was necessary for intimacy in close relationships. Intimacy has been shown to be an important component of friendships beginning in adolescence (Hartup 1996), and advances in the level of intimacy persist into early adulthood (Reis et al. 1993). Our sample consisted of emerging adults nearly all of whom had best friendships and many of whom had romantic relationships. Moreover, we measured intimacy in terms of expression rather than capability. Additionally, considerably more emerging adults reported that their best friendships were longer in duration (i.e., $92.7 \%$ lasting more than a year) compared to their romantic relationships (i.e., $34.2 \%$ lasting more than a year). Thus, perhaps most of these individuals were attending to their comparatively new close relationships with their exclusive romantic partners to fulfill their needs for emotional intimacy, despite being capable of forming and maintaining intimate relations with friends. Longitudinal studies that track the capacity for intimacy and expression of intimacy across adolescence and adulthood in friendships and romantic relationships are necessary to test this proposition. Thus, future research is needed to determine if the lack of a relation between identity and friendship intimacy is unique to emerging adults with both friendship and romantic relationships compared to those with friendships only, or whether this nonsignificant relation persists into adulthood.
The unexpected negative relation between independence and four romantic relationship qualities might be explained by the fact that the independence adulthood criteria are individualistic rather than relational. As a result, it is possible that the task of becoming independent is at cross purposes with forming a romantic relationship with good alliance, intimacy, aid, and emotional support. Thus, the lack of significance between independence (i.e., focus on self) and relationships (i.e., focus on other) is perhaps not as surprising as was initially thought.

The achieved adulthood criteria of interdependence was related positively to the friendship qualities of affection (rather than a negative relation) and relationship satisfaction (rather than a nonsignificant relation). These findings suggest that at least with respect to being other-oriented, the transition to adulthood may benefit not only emerging adults' romantic relationship qualities, but also some of their friendship qualities.

\section{Identity Status and Relationship Qualities}

The study's results indicated that only identity achievement was related significantly and positively to companionship, worth, affection, and emotional support in romantic relationships. Thus, Erikson's (1968) notion that identity achievement is a precursor to high quality intimate relationships is supported in the case of romantic relationships. Both identity foreclosure and achievement are considered to be adult identities (Lewis 2003), yet identity foreclosure was not related to any of the romantic relationship qualities (nor friendship qualities). The lack of significant relations between foreclosure and relationship qualities is not surprising for this sample because Western culture emphasizes an active approach of defining one's identity that is commensurate with high levels of exploration (i.e., moratorium that leads to achievement) rather than identity foreclosure (Ogbu 1988). In doing so, Westerners are able to forge their own path in a search for individualism (particularly among European Americans who comprised the majority of this sample; Markus and Kitayama 1991). An alternate explanation consistent with work by Meeus et al. (1999) exists: among those identity-foreclosed individuals who may view identity exploration as unnecessary, their identity status may be unrelated to relationship qualities.

\section{Achieved Adulthood Criteria and Relationship} Qualities

In this study, the achievement of adulthood criteria tended to be associated with less positive friendship qualities, but more positive romantic relationship qualities. Together these findings provide further support to Erikson's (1968) notion that identity exploration and commitment 
(i.e., achievement) precedes higher quality intimate relationships with romantic partners. This theory was supported in particular by the significant and positive relations between the achievement of interdependence as an adulthood indicator and all nine romantic relationship qualities. These significant relations also are consistent with a theory of relationship maturity (White et al. 1986, 1987), which consists of three levels: self-focused, role-focused, and individuated-connected. This final level relates to the achieved criteria of interdependence as it involves the connection between people, and the social cognitive abilities (e.g., perspective-taking skills) that foster that connection. Moreover, these results extend Demir's (2008) study on emerging adults who report higher levels of happiness when experiencing both a high-quality romantic relationship and high levels of identity formation. Individuals who develop skills commensurate with acting like an adult in interpersonal experiences with romantic partners thus experience more positive qualities in that relationship.

\section{Gender Differences in Relationship Qualities}

Consistent with the literature (e.g., Collins and Madsen 2006), some gender differences were found for friendships. Specifically, female emerging adults reported greater levels of nurturance, affection, intimacy, and emotional support from their best friends than did male emerging adults. However, few gender differences were found for romantic relationships: female emerging adults only reported more aid in their romantic relationship qualities than did male emerging adults. According to Sullivan (1953), intimacy emerges as a prominent feature of adolescent same-sex friendships. Girls' friendships in late adolescence show greater intimacy than do boys' friendships (Sharabany et al. 1981); however, research on cross-sex friendships (e.g., Kuttler et al. 1999) indicates that adolescent boys experience levels of intimacy in their friendships with girls that are comparable to those experienced by adolescent girls in their same-sex friendships. Perhaps gender differences in relationship experiences, particularly in romantic relationships, are lessening for emerging-adult men and women. Indeed, the pathways by which men acquire intimacy in close relationships involve both self-disclosure and companionship, whereas women need only self-disclosure for such acquisition (Radmacher and Azmitia 2006). For future research, scholars should investigate the possibility that adolescent girls may be socializing boys in the qualities of close relationships (e.g., intimacy), such that romantic relationships are experienced similarly by men and women by the time they reach emerging adulthood.
Limitations

Although the current findings present a fairly clean distinction between friendships and romantic relationships with respect to adulthood indicators that predict these relationship qualities, it is important to realize that for many emerging adults the line between friend and romantic partner may be blurred (for a review, see Crouter and Booth 2006). The Social Provisions Questionnaire (Carbery and Buhrmester 1998) used in this study asks participants to respond to questions about best friends and romantic partners while referencing separate individuals. However, we did not gather data on the identity of the relationship partners; thus, leaving the extent to which this issue impacts our findings unclear. Sexual contact previously assumed to exist solely within romantic relationships has been found within some opposite-sex friendships as well (e.g., Afif and Faulkner 2000). So, emerging adults may still have a close, high-quality friendship; however, they may find this in the same person with whom they have their romantic relationship. If this is true, Weiss' theory may be in need of adjustment, as friends and romantic partners may serve some of the same needs rather than entirely distinct needs. Scholars need to investigate the conceptualization of these close relationships among emerging adults in greater detail to determine the extent of overlap in meaning between these relationships. Nevertheless, it may remain difficult to identify the true nature of a given relationship, to disentangle the extent of overlap in relationship functions, and to differentiate between how adulthood indicators account for relationship qualities with friends and partners.

A second limitation is this study's inclusion of predominantly European-American heterosexual college students. Consequently, it is unclear how adulthood indicators may relate to friendship and romantic relationship qualities among emerging adults who are sexual minorities, ethnically diverse, not pursuing higher education actively, or otherwise marginalized (for a review diverse transitions, see Osgood et al. 2005). For example, identity statuses have been shown to vary as a function of ethnicity and gender (see Lewis 2003). As a result, identity development might relate to relationship qualities in different ways for ethnic minority groups. Similarly, sexual minority young people vary in the timing of their sexual identity development (Savin-Williams and Diamond 2004), and, therefore, there is reason to expect tremendous heterogeneity within close relationship experiences and qualities for this population.

Third, although our sample ranged from 18 to 26 years of age, most of the participants were young emerging adults. Given that there are likely to be important changes as individuals become further entrenched in adult social 
roles, and once the social context of college (and its easy access to friends) is left behind, future scholars should examine how identity development and adulthood criteria are related to close relationships in the latter half of emerging adulthood to determine to what extent the relations remain.

Finally, emerging adults have other important persons in their social network beyond best friends and romantic partners, and the interplay of these relationships has been shown to relate to their adjustment (Galaway and Huston 1996). Some work has been done considering the relation between adulthood indicators and relationships with parents (see Nelson et al. 2007; Shulman and Ben-Artzi 2003), but it would be helpful to study the ensemble of emerging adults' relationships in concert, including groups of friends, mentors, and colleagues.

\section{Conclusion}

The transition to adulthood is a time of feeling "inbetween" the former status of adolescence and the forthcoming status of adulthood (Arnett 2004). The burgeoning literature on this population of emerging adults has shown that they gradually achieve important developmental markers for adulthood, and as they do so their behaviors are more commensurate with those of adults. In this study, emerging adults who move successfully toward adulthood as evidenced by the achievement of adulthood criteria and progress in identity development tend to experience more positive qualities in their romantic relationships, but less positive qualities in their friendships. The study's results thereby suggest that the transition to adulthood has important implications for emerging adults' social adjustment. That is, as they take on adult roles and responsibilities, emerging adults also experience a developmental need to shift their focus from friendships to romantic relationships, thus impacting qualities of these relationships. Just as earlier salient developmental tasks in childhood transform close relationships and evoke adjustments in their qualities in meaningful and predictable ways, so too may the task of becoming an adult. Our understanding of this process will be enhanced by attention to the relation between the achievements of adulthood indicators to other adjustment indicators, including relationship qualities with other important members of emerging adults' social network.

\footnotetext{
Acknowledgments The authors express appreciation to the instructors and participants at all Project READY data collection sites for their assistance. We also are grateful for the junior faculty sabbatical grant given to the first author by Loyola College in Maryland and the grant support of the Family Studies Center, which were invaluable for this manuscript to come to fruition. Finally, we thank Melanie Zimmer-Gembeck and Laura Padilla-Walker for their helpful comments on this paper.
}

\section{References}

Afif, W. A., \& Faulkner, S. L. (2000). On being 'just friends': The frequency and impact of sexual activity in cross-sex friendships. Journal of Social and Personal Relationships, 17, 205-222.

Arnett, J. J. (1997). Learning to stand alone: The contemporary American transition to adulthood in cultural and historical context. Human Development, 41, 295-315.

Arnett, J. J. (2000). Emerging adulthood: A theory of development from the late teens through the twenties. American Psychologist, $55,469-480$.

Arnett, J. J. (2003). Conceptions of the transition to adulthood among emerging adults in American ethnic groups. In J. J. Arnett \& N. L. Galambos (Eds.), New directions in child and adolescent development: Exploring cultural conceptions of the transition to adulthood (Vol. 100, pp. 63-75). San Francisco: Wiley.

Arnett, J. J. (2004). Emerging adulthood: The winding road from the late teens through the twenties. New York: Oxford University Press.

Balistreri, E., Busch-Rossnagel, N. A., \& Geisinger, K. F. (1995). Development and preliminary validation of the Ego Identity Process Questionnaire. Journal of Adolescence, 18, 179-192.

Berndt, T. J. (2004). Children's friendships: Shifts over a half-century in perspectives on their development and their effects. MerrillPalmer Quarterly, 50, 206-223.

Carbery, J., \& Buhrmester, D. (1998). Friendship and need fulfillment during three phases of young adulthood. Journal of Social and Personal Relationships, 15, 393-409.

Carroll, J. S., Willoughby, B., Badger, S., Nelson, L. J., Barry, C. M., $\&$ Madsen, S. D. (2007). So close, yet so far away: The impact of varying marital horizons on emerging adulthood. Journal of Adolescent Research, 22, 219-247.

Cohen, P., Kasen, S., Chen, H., Hartmark, C., \& Gordon, K. (2003). Variations in patterns of developmental transitions in the emerging adulthood period. Developmental Psychology, 39(4), 657-669.

Collins, N. L., Cooper, M. L., Albino, A., \& Allard, L. (2002). Psychosocial vulnerability from adolescence to adulthood: A prospective study of attachment style differences in relationship functioning and partner choice. Journal of Personality, 70, 9651008.

Collins, W. A., \& Laursen, B. (2004). Parent-adolescent relationships and influence. In R. Lerner \& L. Steinberg (Eds.), Handbook of adolescent psychology (pp. 331-362). New York: Wiley.

Collins, W. A., \& Madsen, S. D. (2006). Personal relationships in adolescence and early adulthood. In A. L. Vangelisti \& D. Perlman (Eds.), The Cambridge handbook of personal relationships (pp. 191-209). New York: Cambridge University Press.

Connolly, J. A., \& Johnson, A. M. (1996). Adolescents' romantic relationships and the structure and quality of their close personal ties. Personal Relationships, 3, 185-195.

Crouter, A. C., \& Booth, A. (2006). Romance and sex in adolescence and emerging adulthood: Risk and opportunities. Mahwah, NJ: Lawrence Erlbaum.

Demir, M. (2008). Sweetheart, you really make me happy: Romantic relationship quality and personality as predictors of happiness among emerging adults. Journal of Happiness Studies, 9, 257-277.

Demir, M., \& Weitekamp, L. A. (2006). I am so happy cause today I found my friend: Friendship and personality as predictors of happiness. Journal of Happiness Studies, 8, 181-211.

Dunphy, D. C. (1963). The social structure of urban adolescent peer groups. Sociometry, 26, 230-246.

Dyk, P. H., \& Adams, G. R. (1990). Identity and intimacy: An initial investigation of three theoretical models using cross-lag panel correlations. Journal of Youth and Adolescence, 19, 91-110. 
Erikson, E. H. (1963). Childhood and society. New York: Norton. Erikson, E. H. (1968). Identity: Youth and crisis. New York: Norton.

Erikson, E. H. (1982). The life cycle completed: A review. New York: Norton.

Feiring, C. (1999). Other-sex friendship networks and the development of romantic relationships in adolescence. Journal of Youth and Adolescence, 28, 495-512.

Feldman, S. S., Cauffman, E., Jensen, L. A., \& Arnett, J. J. (2000). The (un)acceptability of betrayal: A study of college students' evaluations of sexual betrayal by a romantic partner and betrayal of a friend's confidence. Journal of Youth and Adolescence, 29, 499-523.

Fraley, R., \& Davis, K. E. (1997). Attachment formation and transfer in young adults' close friendships and romantic relationships. Personal Relationships, 4, 131-144.

Furman, W., \& Buhrmester, D. (1992). Age and sex differences in perceptions of networks of personal relationships. Child Development, 63, 832-837.

Galaway, B., \& Huston, J. (Eds.). (1996). Youth in transition: Perspectives on research and policy. Toronto: Thompson Educational.

Ginsberg, D., \& Gottman, J. M. (1986). Conversations of college roommates: Similarities and differences in male and female friendships. In J. M. Gottman \& J. C. Parker (Eds.), Conversations of friends (pp. 241-291). Cambridge, MA: Cambridge University Press.

Hartup, W. W. (1996). The company they keep: Friendships and their developmental significance. Child Development, 67, 1-13.

Hartup, W. W., \& Stevens, N. (1997). Friendships and adaptation in the life course. Psychological Bulletin, 121, 355-370.

Havighurst, R. J. (1948). Developmental tasks and education. Chicago: University of Chicago Press.

Hays, R. B. (1989). The day-to-day functioning of close versus casual friendships. Journal of Social and Personal Relationships, 6, 21-37.

Iso-Ahola, S. (1980). Who's turning children's little league play into work? Parks and Recreation, 15, 51-54.

Johnson, M. P., \& Leslie, L. (1982). Couple involvement and network structure: A test of the dyadic withdrawal hypothesis. Social Psychology Quarterly, 45, 34-43.

Kuttler, A., La Greca, A., \& Prinstein, M. (1999). Friendship qualities and social-emotional functioning of adolescents with close, cross-sex friendships. Journal of Research on Adolescence, 9, $339-366$

Laursen, B., \& Bukowski, W. M. (1997). A developmental guide to the organization of close relationships. International Journal of Behavioral Development, 21, 747-770.

Lefkowitz, E. S., Boone, T. L., \& Shearer, C. L. (2004). Communication with best friends about sex-related topics during emerging adulthood. Journal of Youth and Adolescence, 33, 339-351.

Lewis, H. L. (2003). Differences in ego identity among college students across age, ethnicity, and gender. Identity, 3, 159-189.

Markstrom, C. A., \& Kalmanir, H. M. (2001). Linkages between the psychosocial stages of identity and intimacy and the ego strengths of fidelity and love. Identity: An International Journal of Theory and Research, 1, 179-196.

Markus, H. R., \& Kitayama, S. (1991). Culture and the self: Implications for cognition, emotion, and motivation. Psychological Review, 98, 224-253.

Matula, K. E., Hustom, T. L., Grotevant, H. D., \& Zamutt, A. (1992). Identity and dating commitment among women and men in college. Journal of Youth and Adolescence, 21, 339-356.

Meeus, W. H. J., Branje, S. J. T., van der Valk, E., \& de Wied, M. (2007). Relationships with intimate partner, best friend, and parents in adolescence and early adulthood: A study of the salience of the intimate partnership. International Journal of Behavioral Development, 31, 569-580.

Meeus, W., Iedema, J., Helsen, M., \& Vollebergh, W. (1999). Patterns of adolescent identity development: Review of literature and longitudinal analysis. Developmental Review, 19, 419-461.

Milardo, R. M., Johnson, M. P., \& Hustom, T. L. (1983). Developing close relationships: Changing patterns of interaction between pair members and social networks. Journal of Personality and Social Psychology, 44, 964-976.

Monck, E. (1991). Patterns of confiding relationships among adolescent girls. Journal of Child Psychology and Psychiatry, 32, 333-345.

Montgomery, M. J. (2005). Psychosocial intimacy and identity: From early adolescence to emerging adulthood. Journal of Adolescent Research, 20, 346-374.

Nelson, L. J., \& Barry, C. M. (2005). Distinguishing features of emerging adulthood: The role of self-classification as an adult. Journal of Adolescent Research, 20, 242-262.

Nelson, L. J., Padilla-Walker, L. M., Carroll, J. S., Madsen, S. D., Barry, C. M., \& Badger, S. (2007). "If you want me to treat you like an adult, start acting like one!" Comparing the criteria for adulthood among emerging adults and their parents. Journal of Family Psychology, 21, 665-674.

Ogbu, J. U. (1988). Cultural diversity and human development. New Directions for Child Development, 42, 11-28.

Osgood, D. W., Foster, E. M., Flanagan, C., \& Ruth, G. R. (2005). On your own without a net: The transition to adulthood for vulnerable populations. Chicago: The University of Chicago Press.

Paul, E. L., \& White, K. M. (1990). The development of intimate relationships in late adolescence. Adolescence, 25, 375-400.

Radmacher, K., \& Azmitia, M. (2006). Are there gendered pathways to intimacy in early adolescents' and emerging adults' friendships? Journal of Adolescent Research, 21, 415-448.

Reis, H. T., Lin, Y., Bennett, M. E., \& Nezlek, J. B. (1993). Change and consistency in social participation during early adulthood. Developmental Psychology, 29, 633-645.

Richards, M. H., Crowe, P. A., Larson, R., \& Swarr, A. (1998) Developmental patterns and gender differences in the experience of peer companionship during adolescence. Child Development, $69,154-163$.

Roisman, G. I., Masten, A. S., Coatsworth, J. D., \& Tellegan, A. (2004). Salient and emerging developmental tasks in the transition to adulthood. Child Development, 75, 123-133.

Sanderson, C. A., \& Cantor, N. (1997). Creating satisfaction in steady dating relationships: The role of personal goals and situational affordances. Journal of Personality and Social Psychology, 73, $1424-1433$.

Savin-Williams, R. C., \& Diamond, L. M. (2004). Sex. In R. M. Lerner \& L. Steinberg (Eds.), Handbook of adolescent psychology (2nd ed., pp. 189-231). Hoboken, NJ: Wiley.

Seginer, R., \& Noyman, M. S. (2005). Future orientation, identity and intimacy: Their relations in emerging adulthood. European Journal of Developmental Psychology, 2, 17-37.

Sharabany, R., Gershoni, R., \& Hofman, J. E. (1981). Girlfriend, boyfriend: Age and sex differences in intimate friendship. Developmental Psychology, 17, 800-808.

Sherman, A. M., DeVries, B., \& Lansford, J. E. (2000). Friendship in childhood and adulthood: Lessons across the life span. International Journal of Aging and Human Development, 51, 31-51.

Shulman, S., \& Ben-Artzi, E. (2003). Age-related differences in the transition to adolescence to adulthood and links with family relationships. Journal of Adult Development, 10, 217-226.

Suh, E. J., Moskowitz, D. S., Fournier, M. A., \& Zuroff, D. C. (2004). Gender and relationships: Influences on agentic and communal behaviors. Personal Relationships, 11, 41-59.

Sullivan, H. S. (1953). The interpersonal theory of psychiatry. New York: Norton. 
Surra, C. A. (1985). Courtship types: Variations in interdependence between partners and social networks. Journal of Personality and Social Psychology, 49, 357-375.

Weiss, R. S. (1974). The provisions of social relationships. In Z. Rubin (Ed.), Doing unto others (pp. 17-26). Englewood Cliffs, NJ: Prentice-Hall.

White, K. M., Speisman, J. C., Costos, D., \& Smith, A. (1987). Relationship maturity: A conceptual and empirical approach. Contributions to Human Development, 18, 81-101.
White, K. M., Speisman, J. C., Jackson, D., Bartis, S., \& Costos, D. (1986). Intimacy maturity and its correlates in young married couples. Journal of Personality and Social Psychology, 50, 152162.

Zimmer-Gembeck, M. J. (1999). Stability, change and individual differences in involvement with friends and romantic partners among adolescent females. Journal of Youth and Adolescence, $28,419-438$. 